\title{
Dental Prophylaxis
}

National Cancer Institute

\section{Source}

National Cancer Institute. Dental Prophylaxis. NCI Thesaurus. Code C62548.

Treatment for the prevention of periodontal diseases or other dental diseases by the cleaning of the teeth in the dental office using the procedures of dental scaling and dental polishing. 